\title{
Calcium Compartmentation in Isolated Renal Tubules in Suspension
}

\author{
Joel M. Weinberg, ${ }^{1}$ Julie A. Davis, and Bharvi Trivedi \\ Division of Nephrology, Department of Internal Medicine, Veterans Administration Medical \\ Center, and University of Michigan, Ann Arbor, Michigan 48109
}

Received September 11, 1987

Recent developments in the use of fluorescent $\mathrm{Ca}^{2+}$ indicators and the electron microprobe have provided major insights into the regulation of cell $\mathrm{Ca}^{2+}$ metabolism (1-3). However, fluorescent dyes are not optimally applicable to all cell types under all study conditions, particularly those involving cell injury, and electron probe microanalysis is complex and requires specialized facilities. Several consistent changes of total cell $\mathrm{Ca}^{2+}$ have been identified during studies of the response of suspensions of isolated renal proximal tubules to oxygen deprivation-induced injury. In particular, tubule cell $\mathrm{Ca}^{2+}$ increases during hypoxic oxygen deprivation and then decreases with reoxygenation (4-6). Tubule cell $\mathrm{Ca}^{2+}$ also increases when tubules are treated with exogenous ATP and then declines (5). Increases of total cell $\mathrm{Ca}^{2+}$ of the magnitude observed must reflect sequestered $\mathrm{Ca}^{2+}(7)$, a conclusion supported by the fact that the increases of cell $\mathrm{Ca}^{2+}$ do not occur under conditions of complete anoxia (6). Because of the proclivity of mitochondria to continue sequestering $\mathrm{Ca}^{2+}$ for long periods after cell disruption and their enormous capacity (7-10), the question remains whether the changes of total cell $\mathrm{Ca}^{2+}$ measured in tubule suspensions reflect sequestration within intact cells or only in irreversibly damaged cells and organelles from such cells already released to the suspending medium. The fact that total $\mathrm{Ca}^{2+}$ falls during reoxygenation could, for example, represent a recovery process that would imply the development of $\mathrm{Ca}^{2+}$ overload during hypoxia in reversibly injured cells or it could simply be due to continued damage of organelles in already lethally injured cells, making them less able to retain sequestered $\mathrm{Ca}^{2+}$ over prolonged periods. The studies in this paper apply techniques for determining $\mathrm{Ca}^{2+}$ compartmentation with digitonin and metabolic inhibitors (11-17) to clarify the basis for the increases of total cell $\mathrm{Ca}^{2+}$ measured in the tubule preparations during hypoxic injury and after treatment with exogenous ATP.

\section{MATERIALS AND METHODS}

Animals. Female New Zealand White rabbits (Shankin's Rabbitry, Warren, MI) weighing an average of $2.5 \mathrm{~kg}$ were used.

\footnotetext{
1 To whom reprint requests should be addressed at Nephrology Division, 3914 Taubman Health Care Center, University of Michigan Medical Center, Ann Arbor, MI 48109-0364.
} 
Tubule isolation. Suspensions enriched in proximal tubules were isolated from rabbit kidney using collagenase to separate the tubules and then Percoll (Pharmacia, Piscataway, NJ) to enrich a proximal tubule fraction as detailed in recent publications $(4,5)$.

General procedures for tubule incubation. The final tubule pellet at the end of the isolation procedure was resuspended to a concentration of 5-7.5 mg tubule protein $/ \mathrm{ml}$ in a $95 \% \mathrm{O}_{2} / 5 \% \mathrm{CO}_{2}$ gassed ice-cold solution containing $105 \mathrm{~mm}$ $\mathrm{NaCl}, 2.1 \mathrm{~mm} \mathrm{KCl}, 25 \mathrm{~mm} \mathrm{NaHCO}, 2.4 \mathrm{~mm} \mathrm{KH}_{2} \mathrm{PO}_{4}, 1.2 \mathrm{~mm} \mathrm{CaCl}, 1.2 \mathrm{~mm}$ $\mathrm{MgCl}_{2}, 1.2 \mathrm{mM} \mathrm{MgSO}_{4}, 0.6 \%$ dialyzed dextran (Pharmacia T-40), $5 \mathrm{~mm}$ glucose, $4 \mathrm{~mm}$ lactate, $1 \mathrm{~mm}$ alanine, and $10 \mathrm{~mm}$ sodium butyrate. Five-milliliter aliquots of this tubule suspension were placed in siliconized 25-ml Erlenmeyer flasks which were then gassed with $95 \% \mathrm{O}_{2} / 5 \% \mathrm{CO}_{2}$, sealed, and kept on ice until use. As they were needed for experiments, flasks were placed in a shaking water bath at $37^{\circ} \mathrm{C}$ and were gently shaken for the desired periods of warm incubation.

Oxygen deprivation of tubule suspensions. To deprive the preparation of oxygen, flasks were gassed with $95 \% \mathrm{~N}_{2} / 5 \% \mathrm{CO}_{2}$ for $5 \mathrm{~min}$. This reduces the medium $\mathrm{O}_{2}$ concentration to less than $10 \mu \mathrm{M}$, which results in a high and consistent degree of oxygen deprivation-induced injury $(4,5)$. The nature and degree of oxygen deprivation were further modulated by controlling the incubation conditions during oxygen deprivation to produce either hypoxic conditions or a high tubule density, simulating more of the conditions present during ischemia in vivo $(4,5)$. For hypoxia studies, tubules were kept in the metabolic shaker and mixed as described above for the entire duration of oxygen deprivation. To study tubules oxygendeprived under high-density-pelleted conditions, the contents of a flask were gassed with $95 \% \mathrm{~N}_{2} / 5 \% \mathrm{CO}_{2}$ for $5 \mathrm{~min}$, and then rapidly transferred to a $15-\mathrm{ml}$ centrifuge tube which was gassed with $95 \% \mathrm{~N}_{2} / 5 \% \mathrm{CO}_{2}$, sealed, and centrifuged in a table-top centrifuge for $15-30 \mathrm{sec}$, a time sufficient to lightly pellet all tubules to the bottom of the centrifuge tube. The tube was then incubated without shaking at $37^{\circ} \mathrm{C}$ for the desired duration of oxygen deprivation. At the end of the oxygen deprivation period, these tubules were resuspended in the full volume of incubation medium by gently inverting the tube several times and either sampled for measurements of $\mathrm{Ca}^{2+}$ as detailed below or regassed with $95 \% \mathrm{O}_{2} / 5 \% \mathrm{CO}_{2}$ for continued incubation under oxygenated conditions.

Measurement of total tubule $\mathrm{Ca}^{2+}$. For measurement of total tubule cell $\mathrm{Ca}^{2+}$ levels, tubules were rapidly separated from their suspending medium by gently layering $0.5 \mathrm{ml}$ of tubule suspension into a $1.5-\mathrm{ml}$ microcentrifuge tube containing $0.7 \mathrm{ml}$ bromododecane (Aldrich, Milwaukee, WI) which had previously been layered on $0.2 \mathrm{ml}$ of $275 \mathrm{~mm}$ sucrose containing 4\% Ficoll (Pharmacia) to increase its density while maintaining its isotonicity. The tube was then centrifuged in a microcentrifuge for $30 \mathrm{sec}$ to pellet the tubules in the bottom sucrose layer. The supernatant that remains above the bromododecane layer was then removed as was the bromododecane. $\mathrm{Ca}^{2+}$ levels of the tubules in the bottom sucrose-Ficoll layer were measured by atomic absorption spectroscopy (18).

Assessment of $\mathrm{Ca}^{2+}$ compartmentation. At the desired sampling time, $0.4-\mathrm{ml}$ aliquots of tubule suspension were added to $1.5-\mathrm{ml}$ microcentrifuge tubes containing $0.2 \mathrm{ml}$ of a reaction medium consisting of $120 \mathrm{~mm} \mathrm{NaCl}, 4 \mathrm{mM} \mathrm{KCl}$, and $20 \mathrm{~mm}$ 


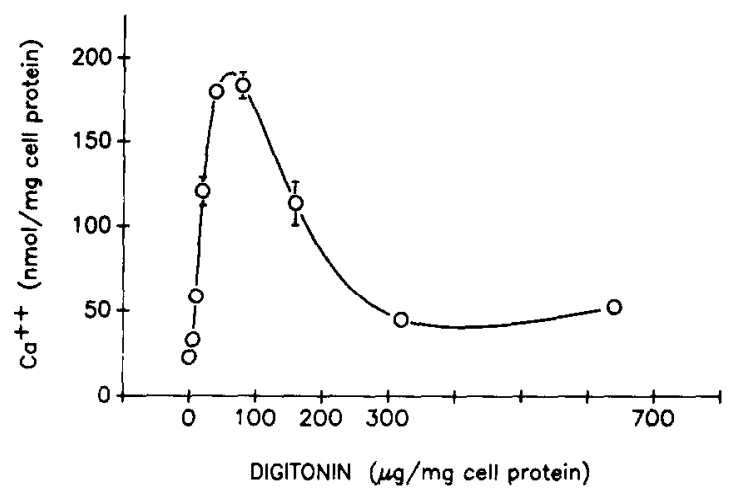

Fig. 1. Effects of the digitonin level on $\mathrm{Ca}^{2+}$ uptake by permeabilized tubules. Tubule suspensions were incubated for $15 \mathrm{~min}$ at $37^{\circ} \mathrm{C}$, then subjected to the $\mathrm{Ca}^{2+}$ compartmentation procedure in the presence of the indicated concentration of digitonin and in the absence of EGTA to permit $\mathrm{Ca}^{2+}$ uptake. Each value is the mean $\pm \mathrm{SE}$ of experiments done at the indicated digitonin level on five separate tubule preparations.

$\mathrm{Na}-\mathrm{Hepes}, \mathrm{pH} 7.4$, at $37^{\circ} \mathrm{C}$. Depending on the experiment, the mixture of tubule suspension and reaction medium also contained varying amounts of digitonin, $3.3 \mathrm{~mm}$ ethylene glycol bis( $\beta$-aminoethyl ether) $N, N^{\prime}$-tetraacetic acid (EGTA), 25 $\mu \mathrm{M}$ carbonyl cyanide $m$-chlorophenyl hydrazone (CCCLP), $30 \mu \mathrm{M}$ A23187, or 50 $\mu \mathrm{M}$ ruthenium red. After $5 \mathrm{~min}$ the tubules were pelleted by centrifugation for $1.5 \mathrm{~min}$ at $12,000 \mathrm{~g}$. The supernatant was removed and saved, and the pellet was resuspended in $0.4 \mathrm{ml}$ of deionized distilled water. Supernatant and pellet samples were then assayed for protein by the Lowry assay (19) and total $\mathrm{Ca}^{2+}$ was measured by atomic absorption spectroscopy (18). Volume corrections for the amount of medium left with the pellet were based on parallel studies with $\left[^{3} \mathrm{H}\right]$ inulin. Volumes of medium measured this way averaged 20.1 and $14.1 \mu \mathrm{l}$ for digitonintreated and untreated tubules, respectively.

Reagents. All reagents were of the highest grade commercially available. Biochemical reagents were obtained from Sigma (St. Louis, MO).

Statistics. Most experiments involved repeated measures and were, therefore, assessed by paired $t$ tests or analysis of variance using models accounting for repeated-measure designs. Individual group comparisons in the multigroup studies were then made using the Newman-Keuls test for multiple comparisons (PC ANOVA, Human Systems Dynamics, Northridge, CA).

\section{RESULTS}

To optimize the conditions required during the compartmentation protocol to fully permeabilize the tubule cells without impairing their mitochondrial $\mathrm{Ca}^{2+}$ sequestering capacity, we initially studied $\mathrm{Ca}^{2+}$ uptake by permeabilized tubules over a range of digitonin concentrations and durations of incubation. Figure 1 shows that maximal $\mathrm{Ca}^{2+}$ uptake occurred after treatment with $40-90 \mu \mathrm{g} / \mathrm{mg}$ tubule cell protein of digitonin. Figure 2 shows that uptake had peaked by $5 \mathrm{~min}$ of incubation, including the time for centrifugation, and was stable for at least 


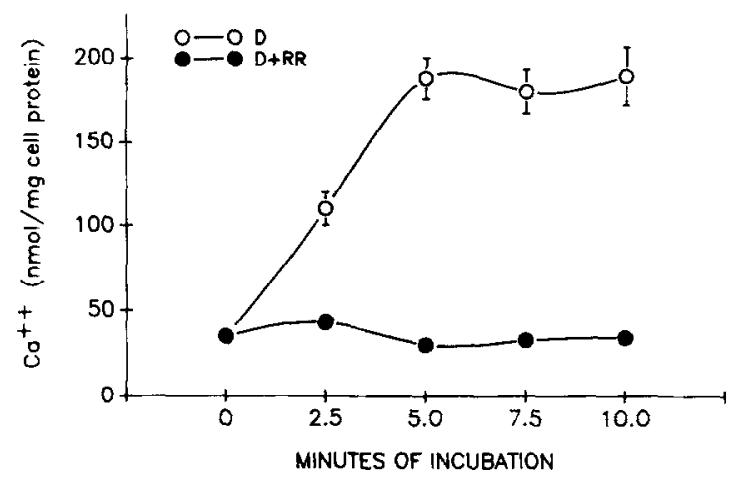

FIG. 2. Time course of $\mathrm{Ca}^{2+}$ uptake by permeabilized tubules. Tubule suspensions were incubated for $15 \mathrm{~min}$ at $37^{\circ} \mathrm{C}$, then subjected to the $\mathrm{Ca}^{2+}$ compartmentation procedure modified to permit the indicated total incubation time including the $1.5 \mathrm{~min}$ of centrifugation. The digitonin (D) level used for this group of experiments averaged $85.8 \pm 1.5 \mu \mathrm{g} / \mathrm{mg}$ cell protein. EGTA was absent in all studies. $D+R R$ indicates tubules incubated in the presence of digitonin plus $50 \mu \mathrm{M}$ ruthenium red.

an additional $5 \mathrm{~min}$. These conditions were, therefore, used for the compartmentation protocol.

Tubules were subjected to a variety of the maneuvers which had produced consistent alterations of total cell $\mathrm{Ca}^{2+}(4-6)$. Figure 3 summarizes measurements of total cell $\mathrm{Ca}^{2+}$ on samples separated from their medium by centrifugation through bromododecane. The pattern of effects was similar to the earlier studies in that control oxygenated tubules showed a progressive decrease of $\mathrm{Ca}^{2+}$ with

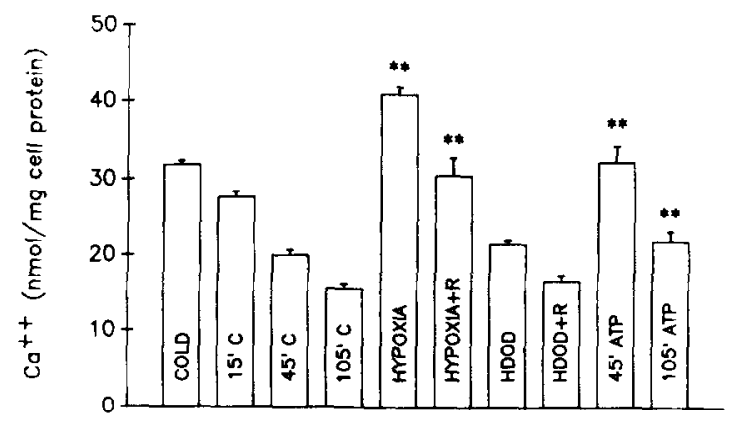

Fig. 3. Total tubule cell $\mathrm{Ca}^{2+}$ levels measured on tubules separated from their medium by centrifugation through bromododecane. "COLD" tubules were studied prior to incubation at $37^{\circ} \mathrm{C}$. " $15^{\prime}$ $\mathrm{C}$," " 45 ' C," and " $105^{\prime} \mathrm{C}$ " were control oxygenated preparations studied after those durations of incubation at $37^{\circ} \mathrm{C}$. "HYPOXIA" tubules were incubated for $15 \mathrm{~min}$ under oxygenated conditions followed by 30 min under hypoxic conditions. "HYPOXIA + R" tubules received an additional 60 min of reoxygenation following hypoxia and were sampled at $105 \mathrm{~min}$ of total incubation. "HDOD" tubules were sampled at the end of $30 \mathrm{~min}$ of oxygen deprivation under high-density (pelleted) conditions. "HDOD $+R^{\prime}$ " tubules received an additional 60 min of reoxygenation following HDOD and were sampled at 105 min of total incubation. "45' ATP" and "105' ATP" tubules were treated with $250 \mu \mathrm{M} \mathrm{Mg-ATP}$ at $15 \mathrm{~min}$ of incubation and were sampled at 45 and $105 \mathrm{~min}$ of total incubation, respectively. Values are means $\pm \mathrm{SE}$ for experiments on five separate tubule preparations. ${ }^{* *} P<$ 0.01 vs corresponding oxygenated time control group. 


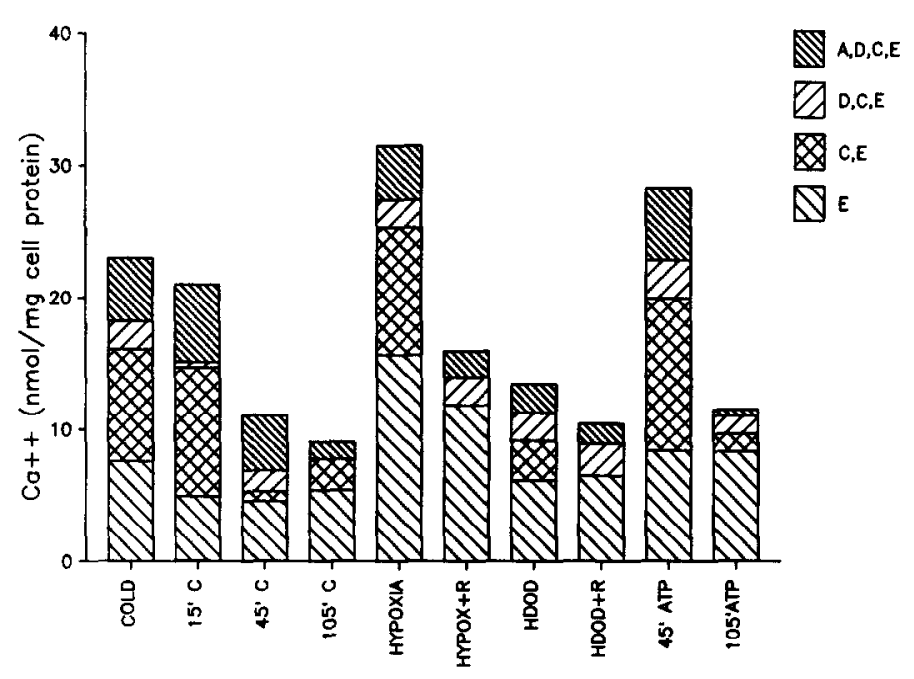

FIG. 4. $\mathrm{Ca}^{2+}$ compartmentation studies done on the experimental groups described in Fig. 3. The data shown arc the amounts of $\mathrm{Ca}^{2+}$ incrementally removed from the tubules by each indicated treatment. $\mathrm{E}, \mathrm{Ca}^{2+}$ removed by exposing intact tubules to EGTA;, $\mathrm{E}$, additional $\mathrm{Ca}^{2+}$ removed by exposing EGTA-treated tubules to CCCLP; D,C,E, additional $\mathrm{Ca}^{2+}$ removed by exposing EGTA + CCCLP-treated tubules to digitonin $\left(74.2 \pm 2.7 \mu \mathrm{g} / \mathrm{mg}\right.$ cell protein); A,D,C,E, additional $\mathrm{Ca}^{2+}$ removed by exposing EGTA + CCCLP + digitonin-treated tubules to A23187. Each value is the mean of experiments done on five separate tubule preparations.

time of incubation, hypoxic tubules had a sharp rise of $\mathrm{Ca}^{2+}$ which then decreased during reoxygenation, tubules which were oxygen-deprived at high density did not have increases of $\mathrm{Ca}^{2+}$, and tubules treated with exogenous ATP had acute rises of $\mathrm{Ca}^{2+}$ which then diminished with time.

Figure 4 shows the amounts of $\mathrm{Ca}^{2+}$ released from these tubule preparations during the compartmentation studies. Treatment of the intact tubules with EGTA released about 5-8 nmole $\mathrm{Ca}^{2+} / \mathrm{mg}$ protein in all groups except for the hypoxia and hypoxia + recovery tubule groups, where significantly larger amounts of $\mathrm{Ca}^{2+}$ were removed $(P<0.01)$. The amount of $\mathrm{Ca}^{2+}$ removed by EGTA was not substantially diminished by $50 \mu \mathrm{m}$ ruthenium red in any of the experimental groups (data not shown).

The amount of additional $\mathrm{Ca}^{2+}$ released by exposing EGTA-treated tubules to CCCLP differed among the groups (Fig. 4). In control oxygenated tubules, CCCLPreleasable $\mathrm{Ca}^{2+}$ progressively decreased with increasing time of incubation at $37^{\circ} \mathrm{C}(P<0.01)$. It was much greater in hypoxic than in time control tubules $(P<0.01$, hypoxia vs $45 \mathrm{~min}$ control), then virtually disappeared when hypoxic tubules were reoxygenated $(P<0.01$, hypoxia vs hypoxia + reoxygenation). In contrast, CCCLP-releasable $\mathrm{Ca}^{2+}$ in tubules oxygen-deprived under high-density conditions as pellets was not significantly higher than in time controls. CCCLPreleasable $\mathrm{Ca}^{2+}$ was very high in ATP-treated tubules at 45 min of incubation $(P<0.01$ vs $45 \mathrm{~min}$ control), then decreased $(P<0.01,45 \mathrm{~min}$ ATP vs $105 \mathrm{~min}$ ATP), and was not significantly different from the time control at $105 \mathrm{~min}$ of incubation. 
The amount of additional $\mathrm{Ca}^{2+}$ released by exposing EGTA + CCCLP-treated tubules to digitonin was relatively small in all groups and differences among them were not statistically significant (Fig. 4).

Addition of the divalent cation ionophore A23187 to EGTA + CCCLP + digitonin released a final increment of $\mathrm{Ca}^{2+}$ in all groups. This $\mathrm{Ca}^{2+}$ release was maximal by the end of the 5-min compartmentation protocol. It was quantitatively similar in 45 min controls, hypoxic tubules, and $45 \mathrm{~min}$ ATP-treated tubules and then tended to decrease as these groups were incubated for an additional 60 min under oxygenated conditions $(P<0.05$ for time controls, $P<0.01$ for ATP-treated, $P$ not significant for hypoxia groups). A23287-releasable $\mathrm{Ca}^{2}$ was slightly but not significantly lower in tubules oxygen-deprived under high-density conditions than in time controls and did not change during reoxygenation.

As shown in Fig. 3, both hypoxic and ATP-treated $\mathrm{Ca}^{2+}$-loaded tubules appear to "recover" since $\mathrm{Ca}^{2+}$ drops during 60 min reoxygenation after hypoxia and is lower in the ATP-treated tubules at 105 min incubation than at $\mathbf{4 5}$ min incubation. The data in Fig. 4, however, indicate that most of these changes in $\mathrm{Ca}^{2+}$ can be attributed to pools that can be released by treatment of cells using only EGTA and CCCLP, without measures such as digitonin or A23187 treatment that would affect permeability of the plasma membranes of intact cells. This suggests that the bulk of the elevated $\mathrm{Ca}^{2+}$ is in free mitochondria and in mitochondria of cells already damaged to the point of lethal cell injury. The apparent recovery seen during longer incubations would then be explained by spontaneous loss of $\mathrm{Ca}^{2+}$ from the free mitochondria following the initial uptake phase.

Spontaneous release of $\mathrm{Ca}^{2+}$ could occur because the damaged tubules and free mitochondria remain suspended in the normal incubation medium which contains abundant $\mathrm{Ca}^{2+}$ and phosphate, conditions which initially favor extensive mitochondrial $\mathrm{Ca}^{2+}$ uptake but then promote $\mathrm{Ca}^{2+}$-mediated inner mitochondrial membrane damage with loss of the accumulated $\mathrm{Ca}^{2+}(8,20)$. The experiments summarized in Fig. 5 were designed to quantify the extent to which this occurs under the conditions used for tubule incubation. Digitonin was used to deliberately permeabilize intact tubules which had been incubating at either 4 or $37^{\circ} \mathrm{C}$ in the normal tubule-suspending medium. Incubation was then continued at $37^{\circ} \mathrm{C}$ with periodic sampling for determination of total tubule cell $\mathrm{Ca}^{2+}$. This procedure differs from the studies summarized in Figs. 1 and 2 where tubules were incubated for only 5-10 min after being mixed with a reaction medium containing digitonin.

Irrespective of whether tubules were initially at 4 or $37^{\circ} \mathrm{C}_{, \mathrm{Ca}^{2+}}$ levels immediately rose to approximately $200 \mathrm{nmole} / \mathrm{mg}$ cell protein, reflecting uptake of virtually all suspending medium $\mathrm{Ca}^{2+}$. They remained at that level between 10 and 25 min and then spontaneously fell to values approaching initial $\mathrm{Ca}^{2+}$ levels.

To test whether ATP-promoted uptake of $\mathrm{Ca}^{2+}$ by free mitochondria and that in permeabilized tubules could contribute to the increases of $\mathrm{Ca}^{2+}$ measured in our system (5), $0.4 \mathrm{ml}$ of tubules was added to $0.2 \mathrm{ml}$ of the $\mathrm{Ca}^{2+}$ compartmentation reaction medium containing digitonin $(75.4 \pm 1.5 \mu \mathrm{g} / \mathrm{mg}$ protein) and supplemental $\mathrm{Ca}^{2+}$ to produce a final concentration of $3 \mathrm{~mm}$ so that $\mathrm{Ca}^{2+}$ availability did not limit uptake. After $5 \mathrm{~min}$ of incubation untreated tubules had $236.4 \pm 6.9$ nmole 


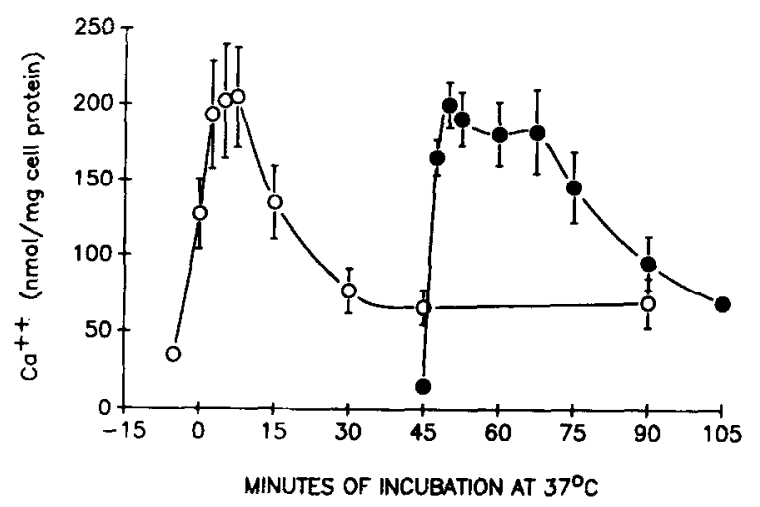

FrG. 5. $\mathrm{Ca}^{2+}$ levels of tubules acutely permeabilized with digitonin, left in the regular suspending medium and sequentially sampled during the indicated periods of incubation at $37^{\circ} \mathrm{C}$. Values are means \pm SE. Open circles are for data from tubules treated with digitonin $(33.8 \pm 2.5 \mu \mathrm{g} / \mathrm{mg}$ cell protein) while still cold 5 min prior to beginning incubation at $37^{\circ} \mathrm{C}(n=3)$. Solid circles are for data from tubules treated with digitonin $(29.6 \pm 0.8 \mu \mathrm{g} / \mathrm{mg}$ protein) at $45 \mathrm{~min}$ of incubation followed by continued incubation for a total of $105 \min (n=5)$.

$\mathrm{Ca}^{2+} / \mathrm{mg}$ cell protein, while tubules permeabilized in the presence of $250 \mu \mathrm{M}$ ATP had $329.0 \pm 5.3$ nmole $\mathrm{Ca}^{2+} / \mathrm{mg}$ cell protein $(P<0.05, n=4)$.

\section{DISCUSSION}

The question whether measurements of total cell $\mathrm{Ca}^{+}$levels on suspensions of isolated kidney tubules can provide insight into pathogenetically important alterations of cell $\mathrm{Ca}^{2+}$ homeostasis in reversibly injured cells or uninjured cells exposed to exogenous ATP, as opposed to simply reflecting changes in the population of cells which is already lethally injured, and in free mitochondria released from these cells, has been addressed.

This issue is relevant because fluorescent methods for measuring cytosolic $\mathrm{Ca}^{2+}$ have been difficult to apply to the freshly isolated tubules. Some success has been reported in preliminary studies (21), but the results are not as clearcut as in cultured cells or fresh cells from other tissues $(2,22)$ and many questions remain about the role of altered $\mathrm{Ca}^{2+}$ homeostasis in the development of injury to the isolated tubules (4-6).

Although not an accurate index of cytosolic $\mathrm{Ca}^{2+}$, total cell $\mathrm{Ca}^{2+}$ levels can nonetheless be useful in assessing the role of $\mathrm{Ca}^{2+}$ in cell injury because elevations of total cell $\mathrm{Ca}^{2+}$ of intact cells not yet lethally injured indicate that a disturbance of cell $\mathrm{Ca}^{2+}$ homeostasis requiring the activation of sequestration mechanisms, predominantly mitochondrial, has occurred $(7,10)$.

It has recently been reported, using electron probe microanalysis of a similar rabbit tubule preparation, that marked heterogeneity between cells exists even in normal control tubule preparations. The majority of cells contain negligible mitochondrial $\mathrm{Ca}^{2+}$ and have high levels of cytosolic $\mathrm{K}^{+}$, suggesting good retention of normal cell membrane permeability and functional properties (23). The absence of substantial sequestered intracellular $\mathrm{Ca}^{2+}$ is consistent with findings in studies 
of hepatocytes by similar techniques (3). However, a subpopulation of tubule cells is characterized by high levels of mitochondrial $\mathrm{Ca}^{2+}$ and relatively low cytosolic $\mathrm{K}^{+}$, indicating substantial damage (23). Cell to cell heterogeneity of $\mathrm{Ca}^{2+}$ distribution has also been documented in injured cultured myocytes (24).

Although extremely powerful, electron probe microanalysis is not universally available and is cumbersome to apply to large numbers of samples. We have, in these studies, therefore, applied an alternative approach to assess the subcellular compartmentation of $\mathrm{Ca}^{2+}$ in the isolated tubule preparation. This involved using digitonin and agents which impair subcellular sequestration of $\mathrm{Ca}^{2+}$.

Previous studies using such approaches have been mainly with isolated hepatocytes and myocytes. They assessed $\mathrm{Ca}^{2+}$ distribution either in very high quality preparations of normal cells (12-14) or during injury characterized by no changes or decreases in total cell $\mathrm{Ca}^{2+}(11,16)$. The tubule preparation has much higher total $\mathrm{Ca}^{2+}$ levels than the isolated hepatocytes or myocytes and these levels are further increased by the maneuvers we studied. Two prior reports containing information on $\mathrm{Ca}^{2+}$ compartmentation in the tubule preparation did not extensively evaluate conditions which increased cell $\mathrm{Ca}^{2+}$ and did not focus on distinguishing between changes in intact and severely damaged cells $(15,16)$.

Under our study conditions, digitonin, at a concentration of $40-90 \mu \mathrm{g} / \mathrm{mg}$ tubule protein, rapidly permeabilized the tubule cells but did not impair the ability of their mitochondria to actively sequester and retain $\mathrm{Ca}^{2+}$ for sufficient time to process samples accurately during the compartmentation protocol. These concentrations of digitonin are similar to those which were required for optimal permeabilization of the plasma membrane to ADP during studies of its effects on tubule cell respiration (25).

Treatment with EGTA alone removes superficial $\mathrm{Ca}^{2+}$ rapidly, but depletes $\mathrm{Ca}^{2+}$ from intact cells $(2,26)$ and energized, undamaged free mitochondria $(8,10,27)$ at a slower rate. The retention of large sequestered pools of $\mathrm{Ca}^{2+}$ after treatment with EGTA alone during the compartmentation protocol (Fig. 4) suggests that the fraction of total cell $\mathrm{Ca}^{2+}$ removed by EGTA is a reasonable estimate of the amount bound to superficial sites on intact cells and present within very damaged free mitochondria.

Most prior $\mathrm{Ca}^{2+}$ compartmentation protocols have employed $\mathrm{Ca}^{2+}$-free incubation conditions rather than EGTA (11-17). This was in part dictated by their use of metallochromatic dyes to assess $\mathrm{Ca}^{2+}$ movement. The larger pool of $\mathrm{Ca}^{2+}$ in the tubule preparation allowed measurements by atomic absorption spectroscopy. The use of EGTA permitted us to subject tubules to the compartmentation protocol immediately after the desired experimental maneuver without an intervening wash or cell separation procedures that could themselves have altered the distribution of $\mathrm{Ca}^{2+}$ or types of cells in the preparation.

CCCLP added to EGTA will deenergize mitochondria (10,11-17), releasing their actively sequestered $\mathrm{Ca}^{2+} . \mathrm{Ca}^{2+}$ in free mitochondria will be released directly to the medium and immediately chelated. $\mathrm{Ca}^{2+}$ released from intracellular mitochondria must first be transported across the plasma membrane. That process is potentially rapid, but it requires either ATP to drive the $\mathrm{Ca}^{2+}$-ATPase or a transmembrane $\mathrm{Na}^{+}$gradient to drive $\mathrm{Na}^{+}-\mathrm{Ca}^{2+}$ exchange. Although the relative 
activity of each of these processes in the renal tubule remains to be clarified, both would be expected to be rapidly and coordinately impaired by CCCLP in the isolated tubule preparation since CCCLP-treated, oxygenated tubules decreased their ATP levels to $5.2 \pm 0.4 \%$ of normal within $60 \mathrm{sec}(n=4)$. ATP availability and the transmembrane $\mathrm{Na}^{+}$gradient are further limited in those tubules studied at the end of oxygen deprivation prior to reoxygenation $(4,5)$. For these reasons it is likely that $\mathrm{Ca}^{2+}$ acutely released by CCCLP reflects $\mathrm{Ca}^{2+}$ mainly present in free but still relatively well-energized mitochondria with some contribution by the limited amount of $\mathrm{Ca}^{2+}$ which can be extruded from intact cells.

Digitonin, by eliminating the plasma membrane barrier, facilitates removal of $\mathrm{Ca}^{2+}$ released from mitochondria within intact cells. Thus, the difference between $\mathrm{Ca}^{2+}$ released by CCCLP + EGTA and CCCLP + EGTA + digitonin provides an estimate of the amount of $\mathrm{Ca}^{2+}$ sequestered within the mitochondria of cells which still have relatively intact plasma membranes.

It is of interest that the effects of digitonin on $\mathrm{Ca}^{2+}$ release have generally not been detailed in prior reports using uncouplers to analyze cell $\mathrm{Ca}^{2+}$ compartmentation (11-17). In a study of hepatocytes where its use was mentioned (13), digitonin did not enhance uncoupler-induced $\mathrm{Ca}^{2+}$ release from isolated hepatocytes. This was taken to indicate that the uncoupler itself was sufficient to release all $\mathrm{Ca}^{2+}$ sequestered in mitochondria within cells. In view of recent electron probe X-ray microanalysis data suggesting that mitochondria of intact hepatocytes may not contain sufficient $\mathrm{Ca}^{2+}$ to account for the $\mathrm{Ca}^{2+}$ release observed (3), it is conceivable that the release measured after uncoupler was actually from the small population of damaged, already permeabilized hepatocytes and free mitochondria present in the preparation.

Our data showing that digitonin does not appreciably enhance $\mathrm{Ca}^{2+}$ release from uncoupler-treated tubules suggest that the mitochondrial $\mathrm{Ca}^{2+}$ pool of intact tubule cells remains extremely small under all conditions studied and that the large increases of $\mathrm{Ca}^{2+}$ seen in hypoxic and ATP-treated tubules reflect predominantly changes which have occurred in severely damaged cells and in mitochondria already released from them. Since mitochondria are clearly still capable of sequestering $\mathrm{Ca}^{2+}$ under the hypoxic incubation conditions, the lack of mitochondrial $\mathrm{Ca}^{2+}$ overload in intact cells during hypoxia suggests that cytosolic $\mathrm{Ca}^{2+}$ may not rise in these cells during hypoxia to a degree sufficient to evoke mitochondrial-sequestering mechanisms. This conclusion is consistent with data obtained using fura- 2 in primary cultures of isolated hepatocytes (22) and aequorin in myocytes (28), which showed no effect of severe ATP depletion on cytosolic $\mathrm{Ca}^{2+}$ prior to cell death. A preliminary report using fura-2 in isolated tubules also failed to detect increases of free cytosolic $\mathrm{Ca}^{2+}$ prior to anoxia-induced cell death (21).

Based on effects reported for other cell types, there are several mechanisms by which treatment with exogenous ATP could alter tubule cell $\mathrm{Ca}^{2+}$ metabolism. ATP could activate polyphosphoinositide turnover, resulting in release of $\mathrm{Ca}^{2+}$ from nonmitochondrial intracellular pools (29), it could directly increase plasma membrane $\mathrm{Ca}^{2+}$ permeability (30), it could modify mitochondrial $\mathrm{Ca}^{2+}$ handling within intact cells by altering intracellular nucleotide levels (5), or it could act 
directly on free mitochondria and those in damaged cells to increase their $\mathrm{Ca}^{2+}$ uptake from the medium (8-10). As discussed for the hypoxia-induced increases of total cell $\mathrm{Ca}^{2+}$, the absence of increased uncoupler-sensitive pools requiring digitonin for release after ATP treatment argues against a contribution of mitochondria within intact cells to the changes of total cell $\mathrm{Ca}^{2+}$ and suggests these are predominantly due to the effects of ATP to increase uptake and retention of $\mathrm{Ca}^{2+}$ by frce mitochondria and those in damaged cells.

The final $\mathrm{Ca}^{2+}$ pool assessed with the compartmentation protocol was measured as the difference between $\mathrm{Ca}^{2+}$ left in EGTA, CCCLP, and digitonin-treated tubules and $\mathrm{Ca}^{2+}$ left in EGTA, CCCLP, digitonin, and A23187-treated tubules. At the high concentration used, the ionophore A23187 effectively permeabilizes all subcellular membranes to $\mathrm{Ca}^{2+}(31)$, allowing $\mathrm{Ca}^{2+}$ to be removed by the medium EGTA. In the present study, A23187-releasable $\mathrm{Ca}^{2+}$ did not differ between time controls, hypoxic tubules, and ATP-treated tubules but tended to decrease with increasing incubation time in all groups.

The incremental release of sequestered $\mathrm{Ca}^{2+}$ induced by $\mathrm{A} 23187$ above that induced by mitochondrial uncouplers has generally been attributed to release of nonmitochondrial $\mathrm{Ca}^{2+}$ stores (11-17) and independent variation of mitochondrial and nonmitochondrial sequestered $\mathrm{Ca}^{2+}$ pools as determined by this methodology has been reported for chemically injured hepatocytes (11). Unfortunately, comparison of the effect of A23187 in the presence and absence of digitonin, as was done with CCCLP to discern the intracellular component, is not possible because of the effects of A23187 to freely equilibrate $\mathrm{Ca}^{2+}$ across all intracellular membranes independently of the presence of digitonin. This has been confirmed for our system by direct measurements of $\mathrm{Ca}^{2+}$ removed by A23187 with and without digitonin present: There was no difference.

It is possible that $\mathrm{A} 23187$ releases, in addition to nonmitochondrial $\mathrm{Ca}^{2+}$, a more tightly bound intramitochondrial $\mathrm{Ca}^{2+}$ pool which is not released by CCCLP. This is suggested by unpublished observations we have made on the effects of treating isolated rat renal cortical mitochondria with CCCLP and A23187. Highly enriched isolated mitochondria always had distinct A23187-releasable pools in addition to those released by CCCLP. However, that $\mathrm{Ca}^{2+}$ could also have come from microsomal fragments adherent to the mitochondria or otherwise contaminating the preparation. Further studies will be needed to resolve this issue.

The data in this paper also provide insight into the mechanisms for the decreases of $\mathrm{Ca}^{2+}$ observed over time in oxygenated tubules and during reoxygenation of hypoxic tubules. The study summarized in Fig. 5, where normal tubules were permeabilized with digitonin at $45 \mathrm{~min}$ of incubation and then followed for an additional $60 \mathrm{~min}$, corresponds to the situation where free mitochondria and those in severely damaged cells of hypoxic preparations contribute to the rises of $\mathrm{Ca}^{2+}$ measured at the end of hypoxia. Since the mitochondria cannot indefinitely retain maximal levels of $\mathrm{Ca}^{2+}$ in the tubule incubation medium at $37^{\circ} \mathrm{C}$, much of that $\mathrm{Ca}^{2+}$ is lost during continued incubation so that total levels fall during $60 \mathrm{~min}$ of reoxygenation.

An analogous situation occurs in the freshly isolated, control oxygenated tubules where $\mathrm{Ca}^{2+}$ sequestered at high levels in the small numbers of initially damaged 
tubule cells and their mitochondria is lost during prolonged incubation at $37^{\circ} \mathrm{C}$. The fact that increased $\mathrm{Ca}^{2+}$ levels in oxygenated preparations treated with ATP decline over time can be similarly explained by an effect of ATP to increase $\mathrm{Ca}^{2+}$ uptake by mitochondria from the small population of damaged cells immediately upon exposure to the high levels of ATP. With continued incubation and degradation of the added ATP (5), the same release process seen in the deliberately permeabilized tubules takes place.

\section{SUMMARY}

Substantial increases of total cell $\mathrm{Ca}^{2+}$ have been observed in suspensions of isolated rabbit proximal tubules subjected to hypoxic injury or treated with exogenous ATP followed by apparent recovery with reoxygenation of the hypoxic tubules or continued incubation of ATP-treated tubules. $\mathrm{Ca}^{2+}$ compartmentation studies using digitonin and metabolic inhibitors were done to clarify the basis for these changes. Digitonin, 40-90 $\mu \mathrm{g} / \mathrm{mg}$ tubule protein, rapidly permeabilized the tubule cells and did not impair mitochondrial $\mathrm{Ca}^{2+}$ sequestration. Most of the increases of tubule cell $\mathrm{Ca}^{2+}$ produced by hypoxia and ATP were accounted for by pools which could be rapidly removed by exposure of tubules to EGTA and the uncoupler carbonyl cyanide $m$-chlorophenyl hydrazone without concomitant use of digitonin, suggesting that the changes of $\mathrm{Ca}^{2+}$ predominantly reflect sequestration by mitochondria in severely damaged cells or mitochondria already released to the medium from them. The time course of uptake followed by spontaneous release of mitochondrial $\mathrm{Ca}^{2+}$ from tubule cells deliberately permeabilized with digitonin, then incubated for prolonged periods, indicated that the decreases of tubule cell $\mathrm{Ca}^{2+}$ during reoxygenation of hypoxic suspensions and prolonged incubation of ATP-treated tubules were likely to be attributable to loss of $\mathrm{Ca}^{2+}$ from free mitochondria and those in damaged cells rather than to extrusion by intact cells.

\section{ACKNOWLEDGMENTS}

These studies were supported by NIH Grant DK-34275 and the Veterans Administration. Dr. Weinberg is the recipient of NIH RCDA DK-01337.

\section{REFERENCES}

1. Grynkiewicz, G., Poenie, M., and Tsien, R. Y., J. Biol. Chem. 260, 3440 (1985).

2. Williamson, J. R., Cooper, R. H., Joseph, S. K., and Thomas, A. P., Amer. J. Physiol. 248, C203 (1985).

3. Somlyo, A. P., and Somlyo, A. V., J. Cardiovasc. Pharmacol. 8(Suppl. 8), 42 (1986).

4. Weinberg, J. M., J. Clin. Invest. 76, 1193 (1985).

5. Weinberg, J. M., and Humes, H. D., Amer. J. Physiol. 250, F720 (1986).

6. Takano, T., Soltoff, S. P., Murdaugh, S., and Mandel, L. J., J. Clin. Invest. 76, 2377 (1985).

7. Weinberg, J. M., Sem. Nephrol. 4, 174 (1984).

8. Weinberg, J. M., and Humes, H. D., Amer. J. Physiol. 248, F876 (1985).

9. Fiskum, G., and Lehninger, A. L., Fed. Proc. 39, 2432 (1980).

10. Nicholls, D., and Akerman, K., Biochim. Biophys. Acta 683, 57 (1982).

11. Bellomo, G., Jewell, S. A., Thor, H., and Orreius, S., Proc. Natl. Acad. Sci. USA 79, 6942 (1982).

12. Joseph, S. K., Coll, K. E., Cooper, R. H., Marks, J. S., and Williamson, J. R., J. Biol. Chem. 258, 731 (1983). 
13. Joseph, S. K., and Williamson, J. R., J. Biol. Chem. 258, 10425 (1983).

14. Williamson, J. R., Williams, R. J., Coll, K. E., and Thomas, A. P., J. Biol. Chem. 258, 13411 (1983).

15. Murphy, E., and Mandel, L. J., Amer. J. Physiol. 242, C124 (1982).

16. Mandel, L. J., and Murphy, E., J. Biol. Chem. 259, 11188 (1984).

17. Cheung, J. Y., Leaf, A., and Bonventre, J. V., Amer. J. Physiol. 250, C18 (1986).

18. Weinberg, J. M., Harding, P. G., and Humes, H. D., Exp. Mol. Pathol. 39, 43 (1983).

19. Lowry, O. H., Rosebrough, N. J., Farr, A. I., and Randall, R. J., J. Biol. Chem. 193, 265 (1951).

20. Beatrice, M. C., Palmer, J. W., and Pfeiffer, D. R., J. Biol. Chem. 255, 8663 (1980).

21. Jacobs, W. F., and Mandel, L. J., Fed. Proc. 45, 541 (1986). [Abstract]

22. Lemasters, J. J., DiGiuseppi, J., Niemenin, A-L., and Herman, B., Nature (London) 325, 78 (1986).

23. Lefurgey, A., Ingram, P., and Mandel, L. J., J. Membr. Biol. 94, 191 (1986).

24. Buja, L. M., Hagler, H. K., Parsons, D., Chien, K., Reynolds, R. C., and Willerson, J. T., Lab. Invest. 53, 397 (1985).

25. Harris, S. I., Balaban, R. S., Barrett, L., and Mandel, L. J., J. Biol. Chem. 256, 10319 (1981).

26. Binet, A., Berthon, B., and Claret, M., Biochem. J. 228, 565 (1985).

27. Riley, W. W., Jr., and Pfeiffer, D. R., J. Biol. Chem. 261, 28 (1986).

28. Cobbold, P. H., Bourne, P. K., and Cuthbertson, K. S. R., Basic Res. Cardiol. 80(Suppl. 2). 155 (1985).

29. Charest, R., Blackmore, P. F., and Exton, J. H., J. Biol. Chem. 260, 15789 (1985).

30. Sung, S. J., Young, J. D., Origlio, A. M., Heiple, J. M., Kuback, H. R., and Silverstein, S. C., J. Biol. Chem. 260, 13442 (1985).

31. Babcock, D. F., First, N. L., and Lardy, H. A., J. Biol. Chem. 251, 3881 (1976). 